\title{
Radiculopathy and myelopathy at segments adjacent to the site of a previous anterior cervical arthrodesis.
}

\author{
Alan S. Hilibrand \\ Department of Orthopaedic Surgery, University Hospitals Spine Institute, Case W. Reserve Univ. Sch. of \\ Med.; Rothman Institute, Thomas Jefferson University \\ Gregory D. Carlson \\ Department of Orthopaedic Surgery, University Hospitals Spine Institute, Case W. Reserve Univ. Sch. of \\ Med.; Department of Orthopaedic Surgery, University Hospitals Spine Institute, Case W. Reserve Univ. Sch. \\ of Med. \\ M A Palumbo \\ Department of Orthopaedic Surgery, University Hospitals Spine Institute, Case W. Reserve Univ. Sch. of \\ Med.; Department of Orthopaedic Surgery, Brown University School of Medicine, 2 Dudley Street \\ Follow thes and additional works at: https://jdc.jefferson.edu/rothman_institute \\ Deoartment of Orthopaedic Surgery, University Hospitals Spine Institute, Case W. Reserve Univ. Sch. of

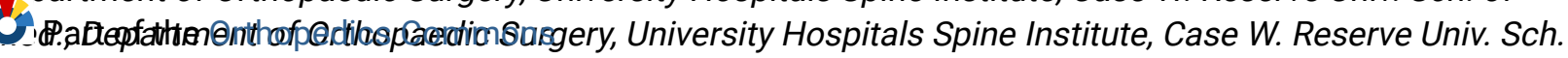 \\ pfépeds know how access to this document benefits you
}

in'ti Bohimain

Recortmentoffedrthpatiohic Surgery, University Hospitals Spine Institute, Case W. Reserve Univ. Sch. of Med.; Department of Orthopaedic Surgery, University Hospitals Spine Institute, Case W. Reserve Univ. Sch. Hilibirand, Alan S.; Carlson, Gregory D.; Palumbo, M A; Jones, P K; and Bohlman, H H,

"Radiculopathy and myelopathy at segments adjacent to the site of a previous anterior cervical arthrodesis." (1999). Rothman Institute Faculty Papers. Paper 8.

https://jdc.jefferson.edu/rothman_institute/8

This Article is brought to you for free and open access by the Jefferson Digital Commons. The Jefferson Digital Commons is a service of Thomas Jefferson University's Center for Teaching and Learning (CTL). The Commons is a showcase for Jefferson books and journals, peer-reviewed scholarly publications, unique historical collections from the University archives, and teaching tools. The Jefferson Digital Commons allows researchers and interested readers anywhere in the world to learn about and keep up to date with Jefferson scholarship. This article has been accepted for inclusion in Rothman Institute Faculty Papers by an authorized administrator of the Jefferson Digital Commons. For more information, please contact: JeffersonDigitalCommons@jefferson.edu. 


\title{
$R$ adiculopathy and $M$ yelopathy at Segments $A$ djacent to the Site of a Previous A nterior Cervical A rthrodesis*
}

\author{
BY ALAN S. HILIBRAND, M.D.†, GREGORY D. CARLSON, M.D.ł, MARK A. PALUMBO, M.D.§, \\ PAUL K. JONES, PH.D.ł, AND HENRY H. BOHLMAN, M.D.ł, CLEVELAND, OHIO \\ Investigation performed at the D epartment of O rthopaedic Surgery, U niversity H ospitals Spine Institute, \\ Case Western Reserve U niversity School of M edicine, Cleveland
}

\begin{abstract}
A bstract
B ackground: We studied the incidence, prevalence, and radiographic progression of symptomatic adjacentsegment disease, which we defined as the development of new radiculopathy or myelopathy referable to a motion segment adjacent to the site of a previous anterior arthrodesis of the cervical spine.

M ethods: A consecutive series of $\mathbf{3 7 4}$ patients who had a total of $\mathbf{4 0 9}$ anterior cervical arthrodeses for the treatment of cervical spondylosis with radiculopathy or myelopathy, or both, were followed for a maximum of twenty-one years after the operation. The annual incidence of symptomatic adjacent-segment disease was defined as the percentage of patients who had been disease-free at the start of a given year of follow-up in whom new disease developed during that year. The prevalence was defined as the percentage of all patients in whom symptomatic adjacent-segment disease developed within a given period of follow-up. The natural history of the disease was predicted with use of a Kaplan-M eier survivorship analysis. The hypothesis that new disease at an adjacent level is more likely to develop following a multilevel arthrodesis than it is following a single-level arthrodesis was tested with logistic regression.
\end{abstract}

R esults: Symptomatic adjacent-segment disease occurred at a relatively constant incidence of 2.9 percent per year (range, 0.0 to 4.8 percent per year) during the ten years after the operation. Survivorship analysis predicted that 25.6 percent of the patients (95 percent confidence interval, 20 to 32 percent) who had an anterior cervical arthrodesis would have new disease at an adjacent level within ten years after the operation. There were highly significant differences among the motion segments with regard to the likelihood of symptomatic

*No benefits in any form have been received or will be received from a commercial party related directly or indirectly to the subject of this article. No funds were received in support of this study.

†R othman Institute at J efferson, 925 Chestnut Street, 5th Floor Philadelphia, Pennsylvania 19107. E-mail address for D r. H ilibrand: alan.hilibrand@mail.tju.edu.

$\ddagger D$ epartment of O rthopaedic Surgery, U niversity H ospitals Spine Institute, Case Western R eserve U niversity School of M edicine, 11100 E uclid A venue, Cleveland, O hio 44106.

$\S D$ epartment of O rthopaedic Surgery, B rown U niversity School of M edicine, 2 D udley Street, Suite 200, Providence, R hode Island 02905.

Copyright 1999 by The Journal of B one and J oint Surgery, I ncorporated adjacent-segment disease $(p<0.0001)$; the greatest risk was at the interspaces between the fifth and sixth and between the sixth and seventh cervical vertebrae. Contrary to our hypothesis, we found that the risk of new disease at an adjacent level was significantly lower following a multilevel arthrodesis than it was following a single-level arthrodesis $(p<0.001)$. M ore than two-thirds of all patients in whom the new disease developed had failure of nonoperative management and needed additional operative procedures.

Conclusions: Symptomatic adjacent-segment disease may affect more than one-fourth of all patients within ten years after an anterior cervical arthrodesis. A single-level arthrodesis involving the fifth or sixth cervical vertebra and preexisting radiographic evidence of degeneration at adjacent levels appear to be the greatest risk factors for new disease. Therefore, we believe that all degenerated segments causing radiculopathy or myelopathy should be included in an anterior cervical arthrodesis. A lthough our findings suggest that symptomatic adjacent-segment disease is the result of progressive spondylosis, patients should be informed of the substantial possibility that new disease will develop at an adjacent level over the long term.

It is believed that arthrodesis of spinal segments leads to excessive stress at unfused adjacent levels. In series of twenty-eight to 146 patients who had had an anterior cervical arthrodesis, 25 to 89 percent who were followed for a long period had new degenerative changes at adjacent levels $s^{1,8,11,12,15,22}$. Thirteen of twentytwo younger patients with Klippel-Feil syndrome who were reexamined in adulthood had radiographic degeneration adjacent to the block vertebrae ${ }^{13}$. In vitro biomechanical studies of the lumbar spine have demonstrated increased load ${ }^{9,20}$, segmental motion, and intradiscal pressure ${ }^{7,20}$ at levels adjacent to simulated arthrodeses.

Several authors have been unable to find an association between radiographic degeneration of adjacent segments and the long-term clinical outcome of anterior cervical discectomy and arthrodesis $6^{6,0,17,22}$. In a magnetic resonance imaging study of the cervical spine in asymptomatic subjects, B oden et al. observed degenerated discs in thirteen of twenty-three subjects who were more than forty years old ${ }^{2}$. Consequently, radiographic degeneration of disc spaces adjacent to the site of a cervical arthrodesis may reflect the natural history of 
TABLE I

Criteria for the A ssessment of Clinical Outcome ${ }^{16}$

\begin{tabular}{llllc}
\hline \hline Outcome & Pain & M edication & A ctivity & Work Status \\
\hline $\begin{array}{l}\text { Excellent } \\
\text { Good }\end{array}$ & None & None & Normal & Normal \\
Fair & M ild & $\begin{array}{c}\text { O ccasional use of nonsteroidal } \\
\text { anti-inflammatory drugs }\end{array}$ & Normal & Normal \\
Poor & Severe & $\begin{array}{c}\text { Frequent use of nonsteroidal } \\
\text { anti-inflammatory drugs } \\
\text { Oral use of narcotics }\end{array}$ & Restricted & Limited \\
\hline \hline
\end{tabular}

cervical spondylosis ${ }^{19}$ and may be meaningful only when it is associated with clinical symptoms of radiculopathy or myelopathy referable to that level.

In contrast to previous studies of radiographic changes following anterior cervical arthrodesis, the present study focused on symptomatic adjacent-segment disease of the cervical spine, which we defined as the development of new radiculopathy or myelopathy referable to a motion segment adjacent to the site of a previous anterior cervical arthrodesis. The goals of the study were (1) to determine the incidence and prevalence of symptomatic adjacent-segment disease in a large population during the first ten years after anterior cervical arthrodesis, (2) to ascertain which cervical motion segments are at greatest risk for new symptoms after an adjacent anterior cervical arthrodesis, (3) to assess whether multilevel arthrodesis is a risk factor for symptomatic disease at an adjacent level, and (4) to determine whether spondylotic changes at levels adjacent to the arthrodesis site are related to the late development of new radiculopathy or myelopathy.

\section{$M$ aterials and M ethods}

B etween 1973 and 1992, 383 patients had a total of 418 anterior cervical arthrodeses, performed at one institution by the senior one of us (H. H. B.), for the treatment of degenerative disease of the cervical spine. $\mathrm{N}$ ine patients were known to have died within six months after the index procedure and therefore were excluded from this analysis, leaving 374 patients (409 procedures). None of these patients had an acute fracture or dislocation, had been managed for a malignant neoplasm, or were scheduled to have a concomitant posterior arthrodesis. There were 180 male patients and 194 female patients; the average age at the time of the index procedure was fifty-one years (range, seventeen to eighty-three years).

Of the 374 patients, twenty-eight had two, two had three, and one had four separate anterior cervical procedures. In order to assess the progression of spondylotic disease after each operative procedure, new adjacent segments were evaluated after each additional operation; thus, 409 separate follow-up evaluations were performed. Of the 409 procedures, 284 were performed in patients who had initially been seen because of neck pain radiating to the arm or shoulder; 103, in those who had initially been seen because of predominantly myelopathic symptoms (such as an unsteady gait or difficulty in handling small objects); and twentytwo, in those who had initially been seen because of both radiculopathy and myelopathy.

B efore the procedure, a history was recorded and a physical examination, including a complete neurological evaluation of strength, sensation, and reflexes, was performed. The indications for operative intervention included failure of a cervical orthosis, physical therapy, and anti-inflammatory analgesics to relieve radicular symptoms or motor-root weakness or evidence of progressive myelopathy according to the history and physical examination with documentation of spinal cord

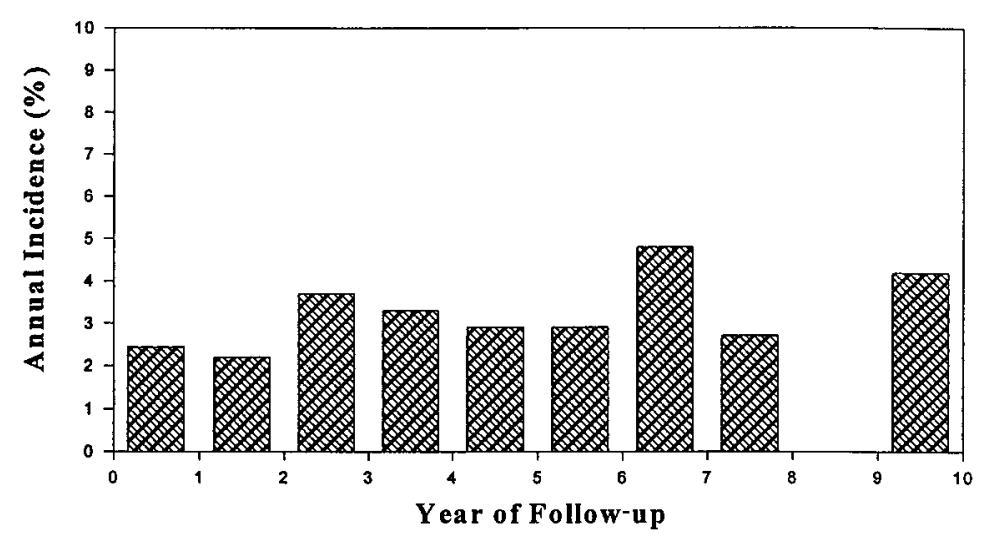

FIG. 1

B ar graph showing the percentages of patients who entered a given year of follow-up disease-free and had subsequent development of new disease during that year. 


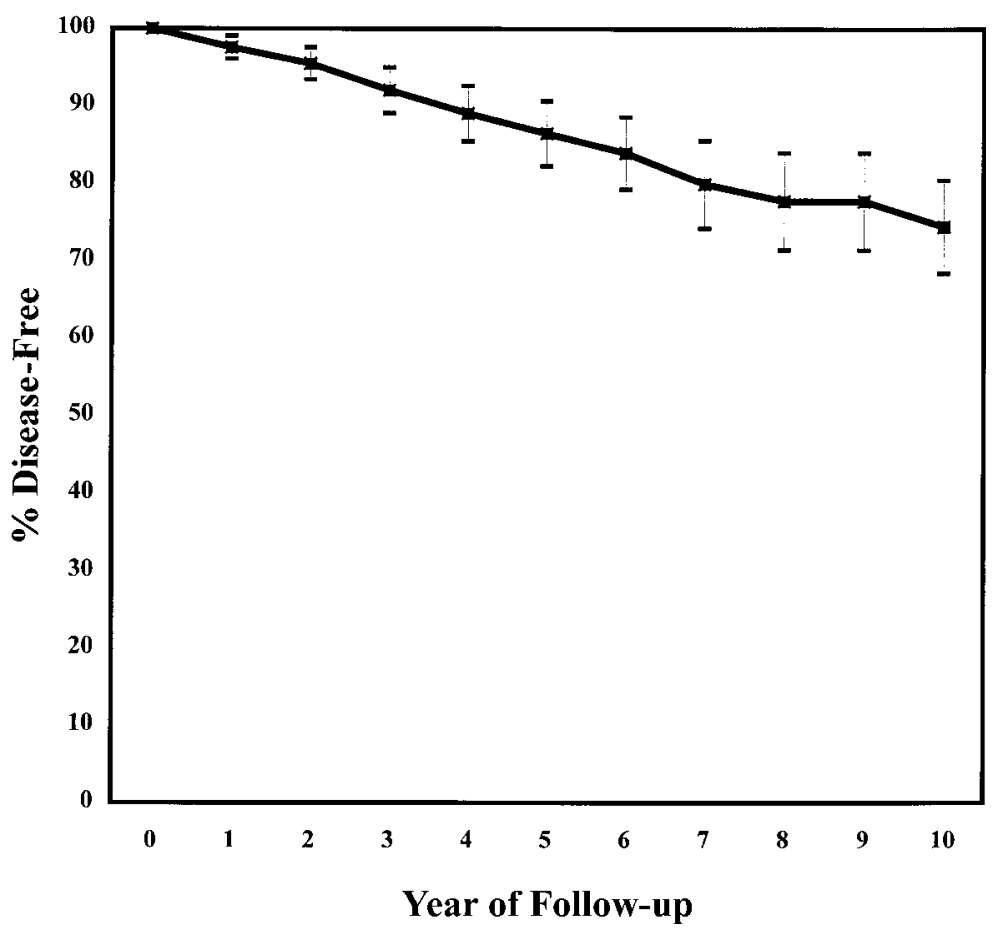

FIG. 2

K aplan-M eier survivorship curve ${ }^{18}$. E ach data-point represents the total percentage of patients who entered a given year of follow-up and were expected to remain free of symptomatic adjacent-segment disease. (The error bars represent the 95 percent confidence intervals at each time-point.)

compression on neuroradiographic imaging.

Preoperatively, all patients had evaluation with plain radiography and myelography in addition to computerized tomography (after 1980) and magnetic resonance imaging (after 1984). Of the 409 procedures, 338 consisted of anterior cervical discectomy and arthrodesis, performed according to a modification of the operative technique described by R obinson and Smith ${ }^{3}$. The procedure was performed at all levels to which clinical signs and symptoms of disease were referable and at which neural element compression was demonstrated on neuroradiographic imaging. There were 168 one-level, 131 two-level, thirty-seven three-level, and two four-level procedures. The remaining seventy-one procedures consisted of subtotal vertebrectomy and arthrodesis with strut-grafting, which was used for patients who had advanced spondylosis or congenital stenosis with spinal cord compression. Autogenous iliac-crest graft was used in forty-one of these procedures and autogenous fibular graft, in thirty. There were twenty one-level, twenty-eight two-level, twentyone three-level, and two four-level corpectomies.

Postoperatively, 354 patients wore a rigid two-poster orthosis for twenty-four hours a day for a total of six weeks, eleven patients used a halo vest, and nine wore a soft cervical collar.

A II patients were examined regularly after the procedure by the senior one of us (H.H. B.). The severity and location of any symptoms, the patient's work status and level of daily activity, and the findings of a complete

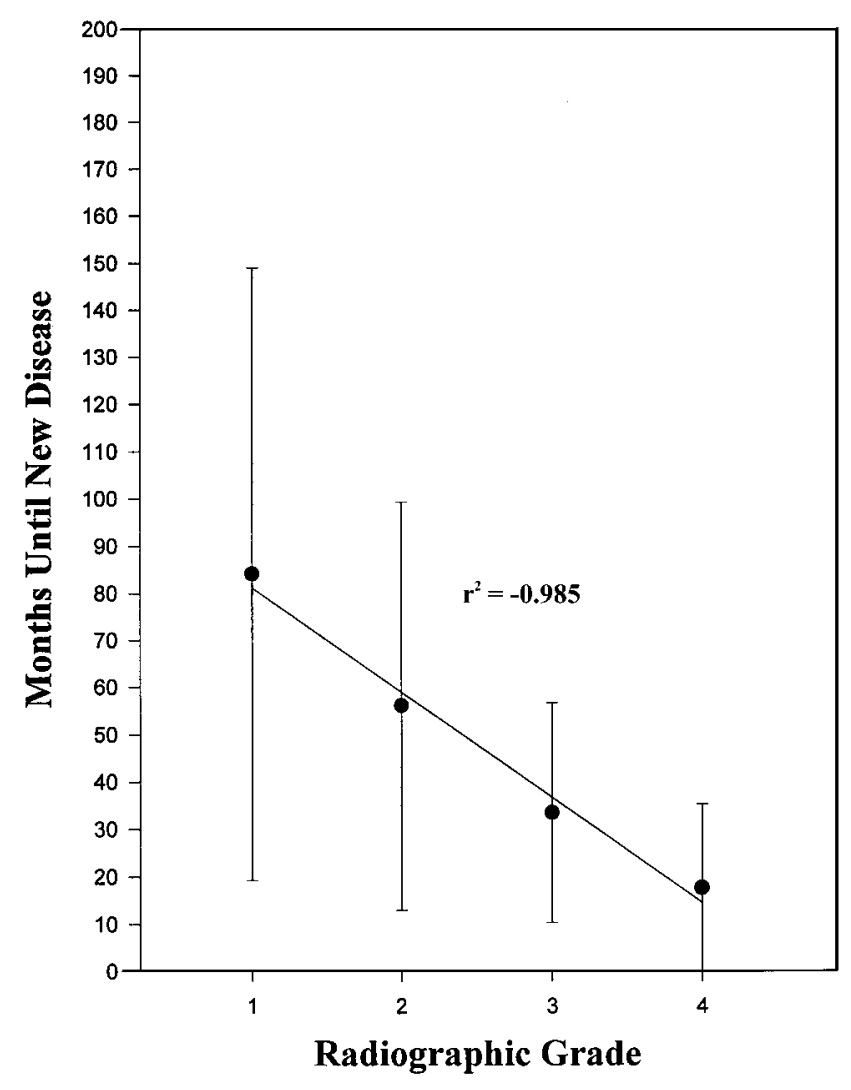

FIG. 3

Graph showing the durations until symptomatic adjacent-segment disease developed according to the radiographic grade for the fortynine patients (fifty procedures) for whom radiographs were available (see Table II). 
TABLE II

Radiographic Grading of Degenerative Changes at Adjacent Levels

\begin{tabular}{|c|c|c|c|c|}
\hline \multirow[b]{2}{*}{ Grade } & \multirow[b]{2}{*}{ D isease } & \multicolumn{3}{|c|}{ Findings } \\
\hline & & $\begin{array}{c}\text { Plain } \\
\text { R adiography }\end{array}$ & $\begin{array}{c}\text { M agnetic } \\
\text { R esonance I maging }\end{array}$ & $\begin{array}{l}\text { Computed Tomography } \\
\text { or M yelography, or B oth }\end{array}$ \\
\hline 1 & None & Normal & Normal & Normal \\
\hline II & Mild & $\begin{array}{l}\text { Narrowing of disc space, } \\
\text { no posterior osteophytes }\end{array}$ & $\begin{array}{l}\text { Signal change in } \\
\text { intervertebral disc }\end{array}$ & Normal \\
\hline III & M oderate & $\begin{array}{l}<50 \% \text { of normal disc height, } \\
\text { posterior osteophytes }\end{array}$ & $\begin{array}{l}\text { H erniated nucleus pulposus } \\
\text { without neural compression }\end{array}$ & $\begin{array}{l}\text { H erniated nucleus pulposus; } \\
\text { no nerve-root cutoff or } \\
\text { spinal cord compression }\end{array}$ \\
\hline IV & Severe & Same as for grade III & $\begin{array}{l}\text { Spinal cord compression } \\
\text { with or without nerve-root } \\
\text { compression }\end{array}$ & $\begin{array}{l}\text { Nerve-root cutoff with or } \\
\text { without spinal cord } \\
\text { compression }\end{array}$ \\
\hline
\end{tabular}

neurological examination, which included strength, sensory, and reflex testing, were documented. L ateral radiographs with the cervical spine in flexion and extension were made at each follow-up visit until a solid fusion or an established pseudarthrosis was noted. Thereafter, anteroposterior and lateral cervical radiographs were made at annual visits.

The hospital and office records for all 409 procedures were reviewed independently by another spine surgeon (A. S. H.), and the diagnosis of symptomatic adjacentsegment disease was based on the presence of new radicular or myelopathic symptoms referable to an adjacent degenerated level on two consecutive visits. N ew radicular symptoms initially were treated with a soft cervical orthosis and non-narcotic analgesics; if the symptoms did not resolve or if new-onset myelopathy was the presenting symptom, magnetic resonance imaging and myelography or computerized tomography, or both, were performed to confirm the presence of a compressive lesion at an adjacent level. The outcome of nonoperative and operative treatment of new disease at an adjacent level was evaluated with use of a modification of the criteria of Robinson et al., which included subjective assessment of pain and objective measurements of the use of medication and the level of activity ${ }^{16}$ (Table I).

A II postoperative radiographs that had been made for the patients who had symptomatic adjacent-segment disease were assessed independently by two of us (A . S. $H$. and M.A.P.). A new system for the qualitative grading of radiographic degenerative changes of the cervical spine was developed. $O \mathrm{n}$ the basis of all available radiographs, adjacent segments were rated as having no disease (grade I), mild disease (grade II), moderate disease (grade III), or severe disease (grade IV) (Table II).

\section{A nalysis of the $D$ ata}

The incidence and the prevalence of symptomatic adjacent-segment disease were calculated for each year with use of life-table methods, with construction of a $K$ aplan-M eier survivorship curve ${ }^{18}$ that included the 409 operative procedures and 95 percent confidence intervals. The annual incidence was defined as the percentage of patients who had been disease-free at the start of a given year of follow-up and had subsequent development of new disease during that year. The prevalence was defined as the percentage of all patients in whom symptomatic new disease developed during a given time-period.

The prevalences of symptomatic adjacent-segment disease among the different motion segments were compared with use of logistic-regression and chi-square analysis. The first open segment caudad and cephalad to each arthrodesis site was considered at risk for the development of new disease. The prevalence of symptomatic disease at an adjacent segment was calculated by

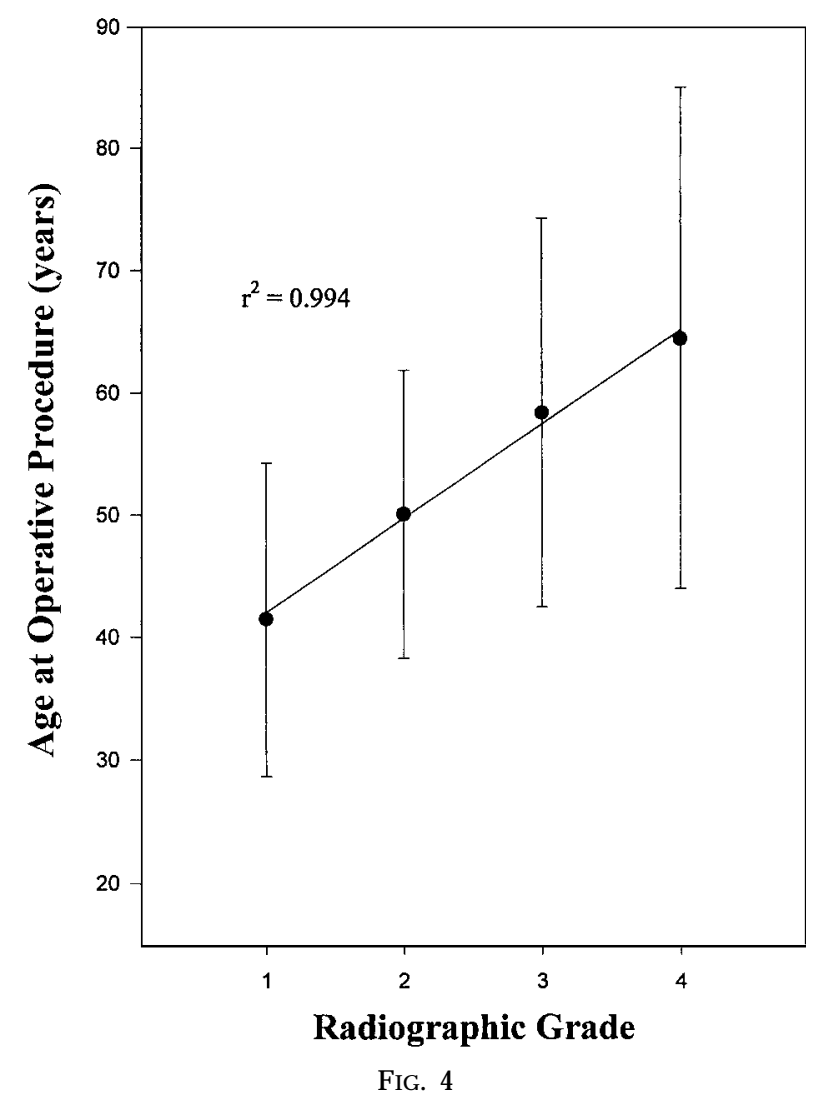

$G$ raph showing the ages at the time of the index operation according to the radiographic grade for the forty-nine patients (fifty procedures) with symptomatic adjacent-segment disease for whom radiographs were available (see Table II) 
TABLE III

Data from the Kaplan-Meier Survivorship Analysis ${ }^{18}$

\begin{tabular}{|c|c|c|c|c|c|c|}
\hline $\begin{array}{c}\text { Yr. of } \\
\text { Follow-up }\end{array}$ & $\begin{array}{l}\text { No. of } \\
\text { Patients } \\
\text { Entered }\end{array}$ & $\begin{array}{l}\text { No. of } \\
\text { Patients L ost } \\
\text { to Follow-up }\end{array}$ & $\begin{array}{c}\text { No. of } \\
\text { Patients with } \\
\text { New D isease }\end{array}$ & $\begin{array}{c}\text { No. of Patients } \\
\text { at R isk at } \\
\text { Follow-up } \\
\text { Interval }\end{array}$ & $\begin{array}{l}\text { Incidence of } \\
\text { New D isease } \\
\text { (percent) }\end{array}$ & $\begin{array}{c}\text { D isease-Free } \\
\text { Survival (R ate } \\
\text { and } 95 \text { Percent } \\
\text { Confidence } \\
\text { Interval) } \\
\text { (percent) }\end{array}$ \\
\hline 1 & 409 & 59 & 9 & 379.5 & 2.4 & $97.6 \pm 1.5$ \\
\hline 2 & 341 & 34 & 7 & 324 & 2.2 & $95.5 \pm 2.1$ \\
\hline 3 & 302 & 61 & 10 & 271.5 & 3.7 & $92.0 \pm 3.0$ \\
\hline 4 & 237 & 44 & 7 & 215 & 3.3 & $89.0 \pm 3.6$ \\
\hline 5 & 188 & 32 & 5 & 172 & 2.9 & $86.4 \pm 4.2$ \\
\hline 6 & 158 & 37 & 4 & 139.5 & 2.9 & $83.9 \pm 4.7$ \\
\hline 7 & 123 & 39 & 5 & 103.5 & 4.8 & $79.9 \pm 5.6$ \\
\hline 8 & 85 & 24 & 2 & 73 & 2.7 & $77.7 \pm 6.2$ \\
\hline 9 & 64 & 16 & 0 & 56 & 0.0 & $77.7 \pm 6.2$ \\
\hline 10 & 53 & 11 & 2 & 47.5 & 4.2 & $74.4 \pm 6.0$ \\
\hline
\end{tabular}

dividing the number of cases of new disease at that segment by the total number of segments at risk for disease. M otion segments with a prevalence of new disease of less than 5 percent were considered to be at low risk; those with a prevalence of 5 to 10 percent, at intermediate risk; and those with a prevalence of more than 10 percent, at high risk.

The hypothesis that there is an association between multilevel arthrodesis and adjacent-segment disease also was tested, and an odds ratio and 95 percent confidence intervals were calculated. Statistical associations between the radiographic grade, the time that it took for the adjacent-segment disease to develop, and the patient's age were determined, with the level of significance set at $p<0.05$.

\section{R esults}

Symptomatic adjacent-segment disease developed following fifty-eight of the 409 procedures (in fifty-five of the 374 patients); this represented an overall prevalence of 14.2 percent (95 percent confidence interval, 10.8 to 17.6 percent). N ew disease at an adjacent level developed at a relatively constant rate in the ten years after the operation (average annual incidence, 2.9 percent [95 percent confidence interval, 1.6 to 4.2 percent] ; range, 0.0 to 4.8 percent) (Fig. 1 ). This resulted in a prevalence of 11.7 percent ( 95 percent confidence interval, 8.5 to 14.8 percent) at five years and 19.2 percent (95 percent confidence interval, 15.4 to 23.0 percent) at ten years. With the numbers available, no significant difference in the development of adjacent-segment disease was observed among the different forms of postoperative immobilization.

A K aplan-M eier survivorship analysis ${ }^{18}$ was performed in order to follow the disease-free survival of the entire series of patients and to take into account the loss of patients to follow-up (Table III). The model predicted an 86.4 percent rate of disease-free survival (95 percent confidence interval, 82.2 to 90.6 percent) at five years and a 74.4 percent rate (95 percent confidence interval, 68.4 to 80.4 percent) at ten years (Fig. 2). This suggests that 13.6 percent of all patients who have anterior cervical arthrodesis will have new disease at an adjacent level within the first five years and that 25.6 percent ( 95 percent confidence interval, 20 to 32 percent) will have new disease within the first ten years after the procedure.

Of the fifty-five patients (fifty-eight procedures) who had symptomatic disease at an adjacent level, forty-six

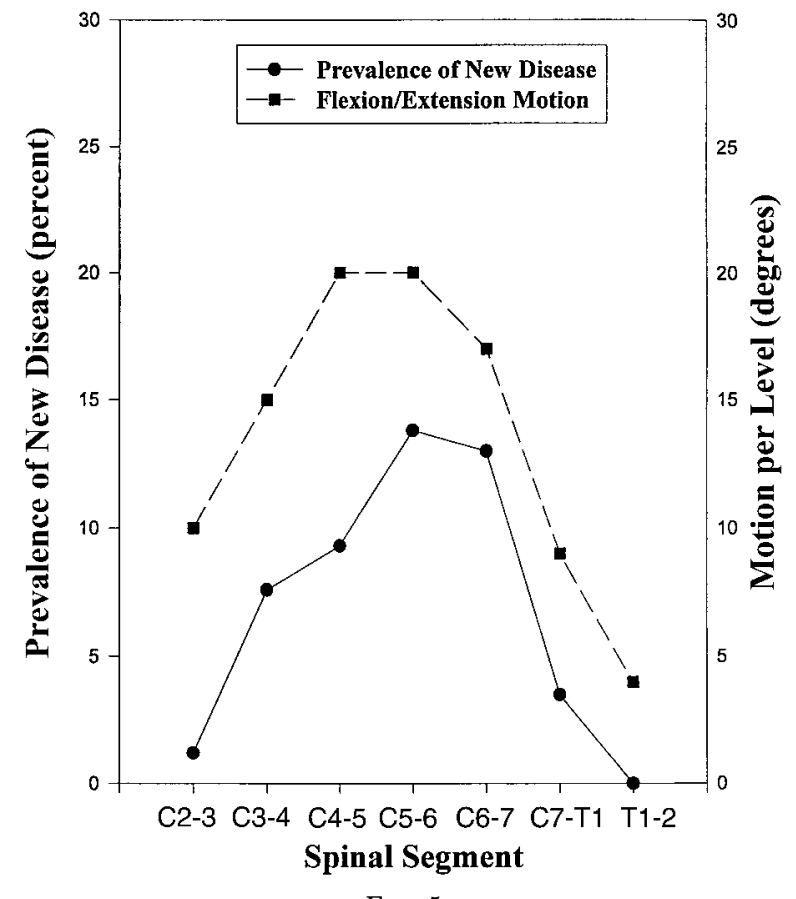

FIG. 5

Graph showing the association between the prevalence of symptomatic adjacent-segment disease at each cervical motion segment and the amount of flexion and extension as described by White and Panjabi24. 


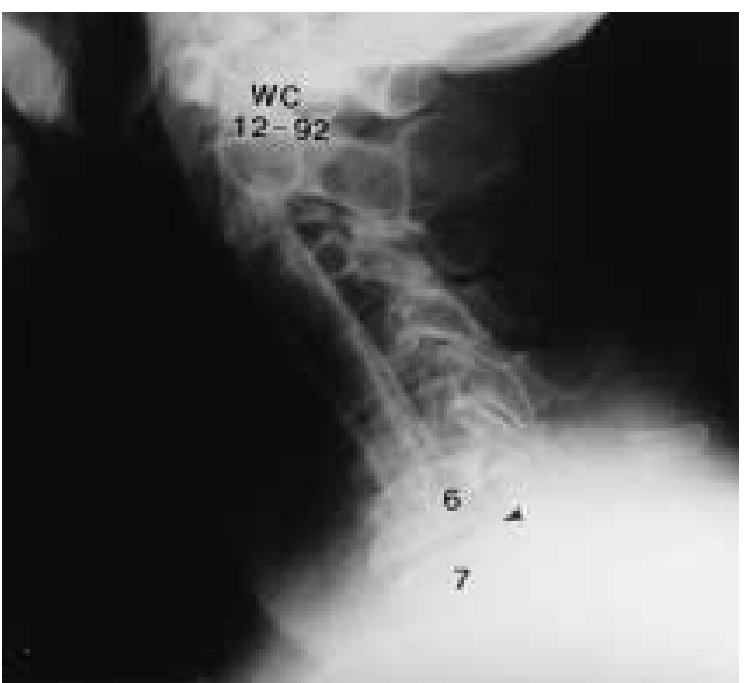

FIG. 6-A

Figs. 6-A , 6-B, and 6-C: A seventy-six-year-old man who had cervical radiculopathy and myelopathy at multiple levels.

Fig. 6-A : L ateral radiograph made after anterior cervical corpectomy and fibular strut-grafting was performed from the second to the sixth cervical vertebra. D egeneration is seen at the sixth and seventh cervical disc level (arrowhead)

(forty-nine procedures) were followed for at least two years after the onset of the new disease. Thirteen patients (fourteen procedures) had successful treatment of the new symptoms with a soft cervical collar, physiotherapy, and anti-inflammatory medications. There were two excellent and twelve good outcomes. Of the patients who did not have improvement after nonoperative treatment, six either refused or were not offered additional procedures and had a fair result. The remaining twenty-seven patients (twenty-nine procedures) had failure of nonoperative management, and anterior cervical decompression and arthrodesis was performed at the adjacent level. Eleven of the twenty-nine procedures led to an excellent result; ten, a good result; and eight, a fair result at the time of the latest follow-up.

There were significant differences among the various motion segments with regard to the relative risk of adjacent-segment disease ( $p<0.0001$; Table IV). The relative risk at the interspaces between the third and fourth and between the fourth and fifth cervical vertebrae (levels at intermediate risk) was 3.2 times that at the interspace between the second and third cervical vertebrae or that at the cervicothoracic interspace (levels at low risk). The relative risk at the interspaces between the fifth and sixth and between the sixth and seventh cervical vertebrae (levels at high risk) was 4.9 times that at the levels at low risk. The differences in relative risk between the low and intermediate-risk groups and between the low and high-risk groups were significant $(p<0.01$ and $p<0.001)$. It should be noted that the new disease developed at an immediately contiguous level, either cephalad or caudad to the site of the previous arthrodesis, or both. In addition, two patients who had had an arthrodesis between the sixth and seventh cervical vertebrae had symptomatic new disease simultaneously between the fifth and sixth and between the fourth and fifth cervical vertebrae.

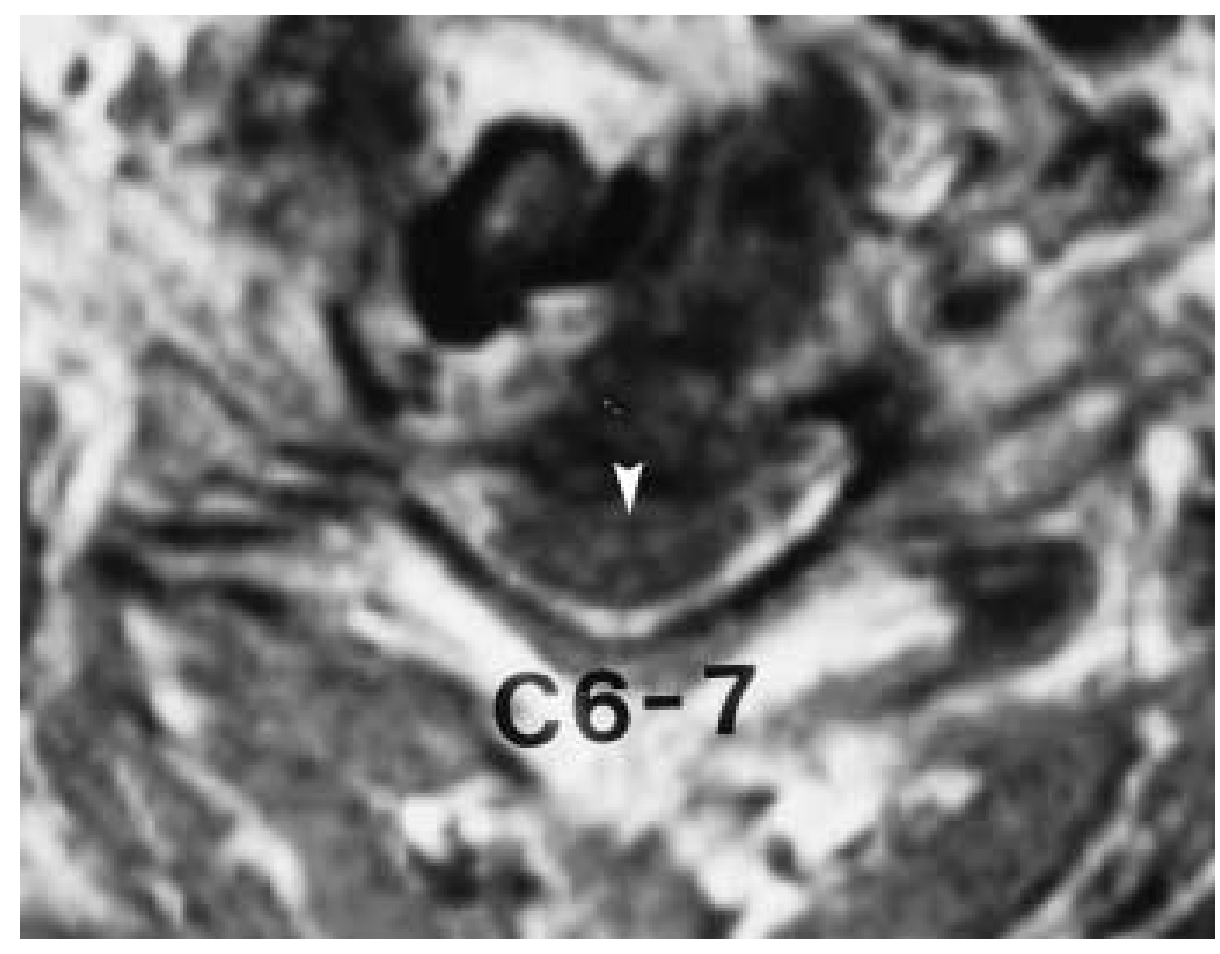

FIG. 6-B

Transverse magnetic resonance image showing a large extradural defect compressing the spinal cord (arrowhead) at the sixth and seventh cervical level. The patient remained symptomatic secondary to the compression. 
TABLE IV

Relative Risk of New Disease Developing at an Adjacent Vertebral Level

\begin{tabular}{|c|c|c|c|c|c|c|c|}
\hline & C2-C3 & C3-C4 & C4-C5 & C5-C6 & C6-C7 & C7-T1 & T1-T2 \\
\hline Total no. of discs at risk & 83 & 105 & 182 & 80 & 161 & 199 & 14 \\
\hline $\begin{array}{l}\text { No. of discs with new } \\
\text { disease }\end{array}$ & 1 & 8 & 17 & 11 & 21 & 7 & 0 \\
\hline Prevalence (percent) & 1.2 & 7.6 & 9.3 & 13.8 & 13.0 & 3.5 & 0.0 \\
\hline R elative risk & Low & Intermediate & Intermediate & $\mathrm{High}$ & $\mathrm{High}$ & Low & Low \\
\hline
\end{tabular}

Contrary to our hypothesis, the risk of symptomatic adjacent-segment disease following multilevel arthrodesis was significantly lower than that following single-level arthrodesis. Of the 256 multilevel arthrodeses, thirty-one (12 percent) were followed by the development of symptomatic adjacent-segment disease compared with twenty-seven (18 percent) of the 153 single-level procedures (odds ratio, $0.64 ; 95$ percent confidence interval, 0.55 to $0.75 ; p<0.001)$.

Of the fifty-five patients (fifty-eight procedures) in whom symptomatic adjacent-segment disease developed, forty-nine patients (fifty procedures) had preoperative radiographs that were available for study. O $\mathrm{n}$ the basis of these radiographs, there was no evidence of disease (grade I) at an adjacent level at the time of eighteen index procedures and there were mild degenerative changes (grade II) at the time of eighteen procedures, moderate degenerative changes (grade III) at the time of twelve, and severe degenerative changes (grade IV) at the time of two (Table II). A significant

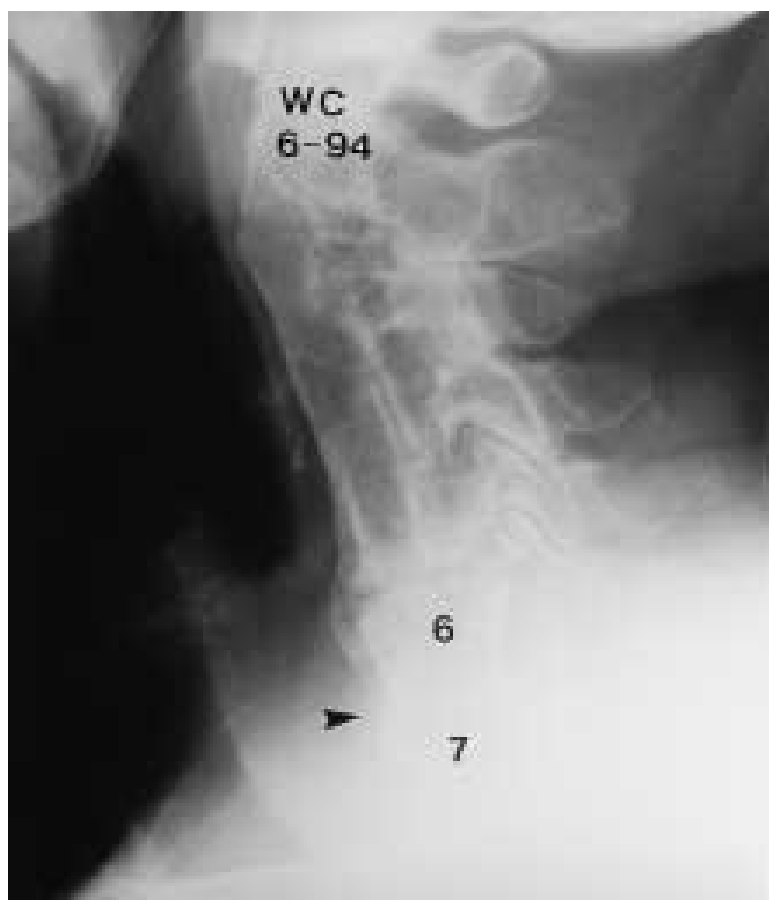

FIG. 6-C

$\mathrm{R}$ adiograph made after anterior cervical decompression and arthrodesis at the sixth and seventh cervical levels (arrowhead). Consolidation of the interbody graft can be seen. The patient had complete resolution of the symptoms. inverse correlation was noted between the degree of radiographic changes at the adjacent level at the time of the procedure and the time until symptomatic disease developed at that level $\left(r^{2}=-0.985\right)$. The average time to the onset of the symptoms was more than seven years in the patients who had no disease (grade I) and less than two years in the patients who had grade-IV changes at an adjacent level at the time of the operation (Fig. 3). In addition, most of the patients who had advanced (grade-III or IV) degenerative changes were older, and there was a significant direct correlation between the patient's age at the time of the operation and the degree of degeneration at the adjacent segment $\left(r^{2}=\right.$ 0.994). The average age at the time of the operation ranged from 41.5 years for the patients who had no changes (grade I) to 64.5 years for those who had severe changes (grade IV) (Fig. 4).

\section{D iscussion}

The present study demonstrated a steady incidence of symptomatic adjacent-segment disease of 2.9 percent per year in the first ten years after anterior cervical decompression and arthrodesis. The prevalence of new disease ten years after the index procedure was 19.2 percent, although K aplan-M eier survivorship anal$\mathrm{ysis}^{18}$ predicted that 25.6 percent of patients would have new disease at ten years. The survivorship analysis should be considered a more accurate assessment of the risk of symptomatic adjacent-segment disease over time because it takes into account censorship or departure of patients from the cohort due to death or loss to follow-up.

The prevalence of adjacent-segment disease in the current study was higher than that reported previously. One of us (H.H. B.) and colleagues reported new radiculopathy, after two to fifteen years of follow-up, in eleven ( 9 percent) of 122 patients who had been managed with a R obinson anterior cervical discectomy and arthrodesis for cervical radiculopathy ${ }^{3}$. A t the time of long-term follow-up, Gore and Sepic reported new radiculopathy at another level in eighteen (14 percent) of 133 patients despite evidence of progressive spondylosis in 50 percent ${ }^{12}$. L unsford et al. performed a reoperation at another level in 7 percent of 253 patients who had had anterior cervical decompression ${ }^{21}$, and $\mathrm{H}$ enderson et al. reported that a reoperation was done because of radiculopathy at another level after 9 percent of 846 


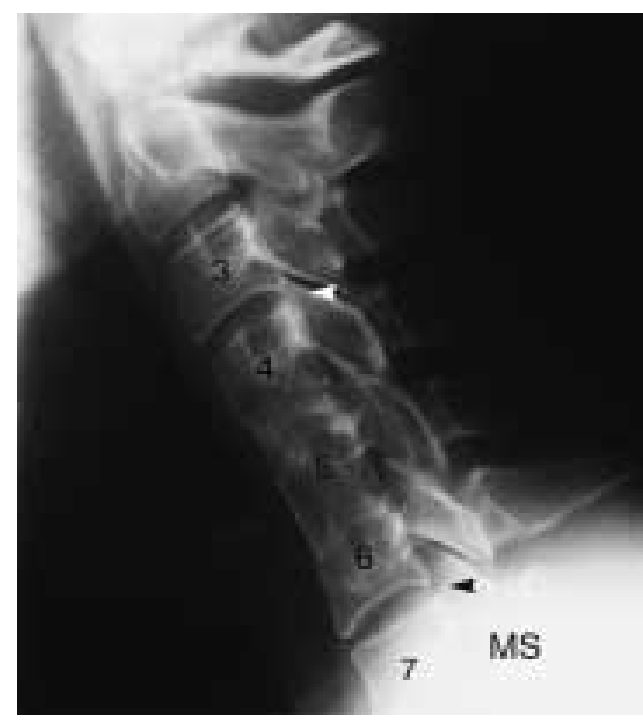

FIG. 7-A

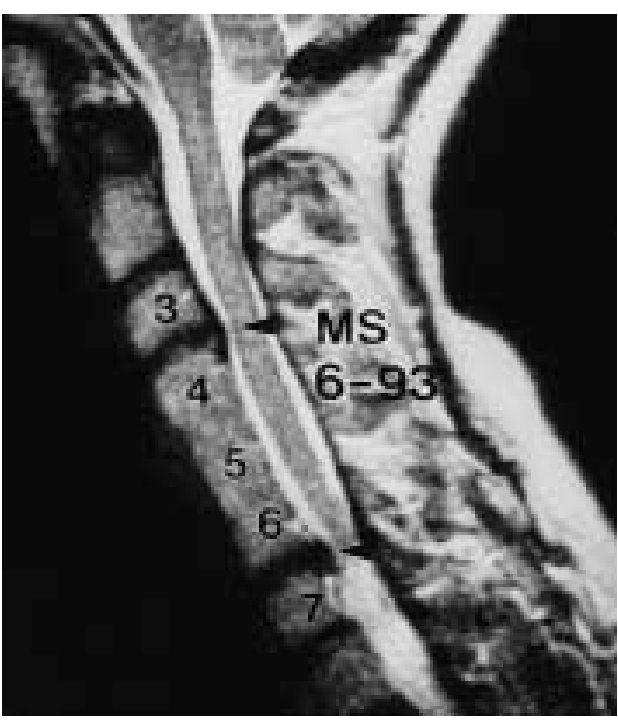

FIG. 7-B

Figs. 7-A and 7-B: A twenty-four-year-old woman who had anterior cervical discectomies and arthrodesis between the fourth and fifth and between the fifth and sixth cervical vertebrae in O ctober 1975. E ighteen years later, new-onset radiculopathy referable to the seventh cervical nerve root developed. Nonoperative treatment led to complete resolution of the symptoms.

Fig. 7-A : L ateral radiograph showing a solid fusion from the fourth to the sixth cervical vertebra with minimum degeneration of the third and fourth and the sixth and seventh cervical disc spaces (arrowheads).

Fig. 7-B: Sagittal magnetic resonance image showing a small bulging of the disc between the third and fourth cervical vertebrae (top arrowhead) and a larger disc herniation between the sixth and seventh cervical vertebrae (bottom arrowhead).

discectomies that had been performed with use of a posterolateral foraminotomy ${ }^{14}$.

The disparity between the findings in the current study and those in previous studies can be attributed to the prediction of new disease over a ten-year period with use of survivorship analysis ${ }^{18}$, the duration of follow-up, and the inclusion of patients who were managed both operatively and nonoperatively for new disease in the current study. We defined symptomatic adjacent-segment disease as new clinical symptoms that persisted for two consecutive follow-up visits. A s already noted, some patients had resolution of the symptoms over time and did not need additional operative procedures. O ther authors may not have included such patients in their studies.

Of the forty-six patients (forty-nine procedures) who were followed for at least two years after new disease developed at an adjacent level, only thirteen (fourteen procedures) responded to nonoperative management. A Ithough we are aware of no long-term follow-up studies on the nonoperative treatment of cervical radiculopathy, Saal et al. reported that twenty of twenty-six patients who were managed nonoperatively for cervical radiculopathy, without having had previous operative management, had a good or excellent result after an average duration of follow-up of two years ${ }^{23}$. This suggests that nonoperative treatment may be less effective in patients who have symptomatic adjacentsegment disease than in those who have primary cervical radiculopathy.

We hypothesized that, after a multilevel arthrodesis, more motion would be transferred to fewer remaining motion segments, leading to a more rapid onset of disc degeneration, chondro-osseous spur formation, and new disease at adjacent levels. Contrary to that hypothesis, we found that patients who had had a multilevel arthrodesis were significantly less likely to have symptom-

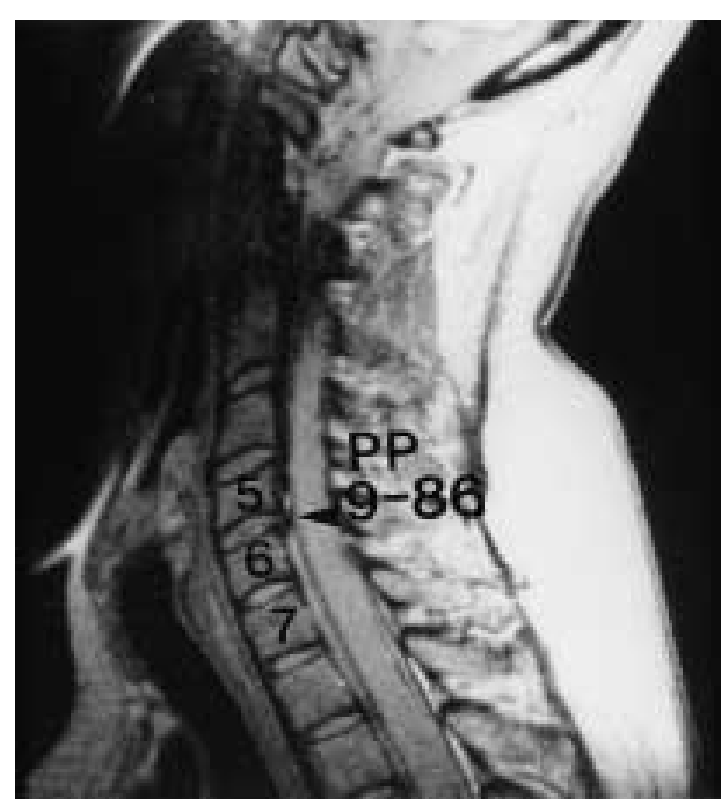

FIG . 8-A

Figs. 8-A , 8-B, and 8-C: A thirty-seven-year-old woman who had anterior discectomy and arthrodesis between the fifth and sixth cervical vertebrae for the treatment of a herniated nucleus pulposus and cervical radiculopathy.

Fig. 8-A : Preoperative magnetic resonance image showing the disc herniation (arrowhead), with a normal-appearing disc between the sixth and seventh cervical vertebrae. 


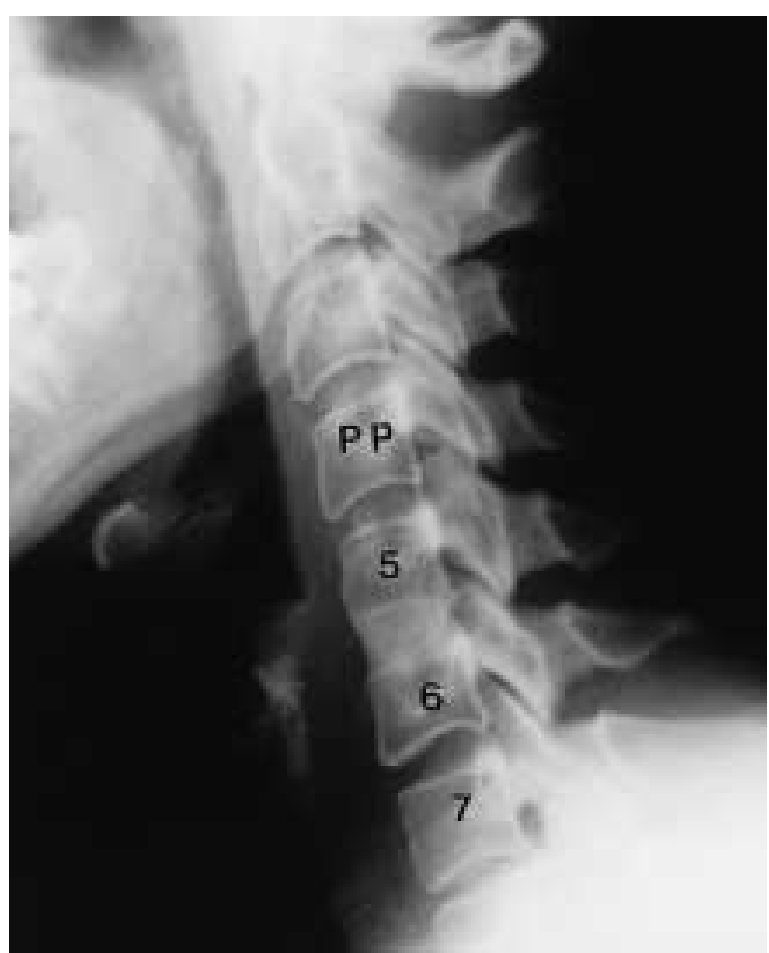

FIG. 8-B

Lateral radiograph made nine months postoperatively, showing consolidation of the interbody graft.

atic adjacent-segment disease than were those who had had a single-level arthrodesis $(p<0.001)$. This finding may be explained by analysis of the levels included in the arthrodesis.

A Ithough cervical spondylosis affects the entire cervical spine, the greatest arthritic changes develop between the fifth and sixth and between the sixth and seventh cervical vertebrae $e^{2-4,12,1,1,2,25}$. Symptomatic adjacentsegment disease also was most common at these levels. Some patients who had had a single-level procedure may have had advanced spondylosis at these higher-risk adjacent levels that was not symptomatic and therefore was not addressed operatively. Symptomatic adjacentsegment disease may have been less common after multilevel arthrodeses as these procedures usually included the higher-risk levels and ended adjacent to segments that were at lower risk for the development of new disease.

We also found a close correlation between the risk of symptomatic adjacent-segment disease and the magnitude of motion at a given level, as described by White and Panjabi ${ }^{24}$. Cervical motion segments with a greater range of motion had a higher prevalence of adjacentsegment disease $\left(r^{2}=0.92 ; p<0.001\right)$ (Fig. 5). D egenerative changes at the most mobile segments of the cervical spine may be part of the biological process of progressive cervical spondylosis and unrelated to an adjacent arthrodesis.

The literature provides additional support for this natural-history explanation of adjacent-segment dis- ease. In 1958, K ellgren and L awrence reported that approximately 50 percent of a normal population will have degenerative changes on plain radiographs of the cervical spine by the age of fifty years ${ }^{19}$. L unsford et al. found no difference in the rate of new radiculopathy at an adjacent level between patients who had had anterior decompression only and those who had had decompression with arthrodesis ${ }^{21}$. H enderson et al. noted new radiculopathy at a different level in 9 percent (seventynine) of 846 patients an average of less than three years after decompression by means of a posterior-lateral foraminotomy without arthrodesis ${ }^{14}$; this represents an average annual incidence of more than 3 percent per year. I is likely that most patients who have any cervical procedure for the treatment of radiculopathy or myelopathy have diffuse cervical spondylosis and may be at greater risk for new disease at another level because of advanced degenerative disease rather than because of the arthrodesis or its extent. Therefore, we believe that symptomatic adjacent-segment disease is the result of progressive cervical spondylosis at adjacent levels and is not caused by the arthrodesis itself.

The radiographic findings in the current study also suggest that symptomatic adjacent-segment disease is related to progressive cervical spondylosis. Patients who had preexisting degenerative changes had a more rapid onset of symptomatic adjacent-segment disease. Patients who were more than sixty years old had more degeneration at the time of the operation than did patients who were less than sixty; this finding is consistent with those of previous studies regarding the natural history of cervical spondylosis ${ }^{2,5}$. Many of these

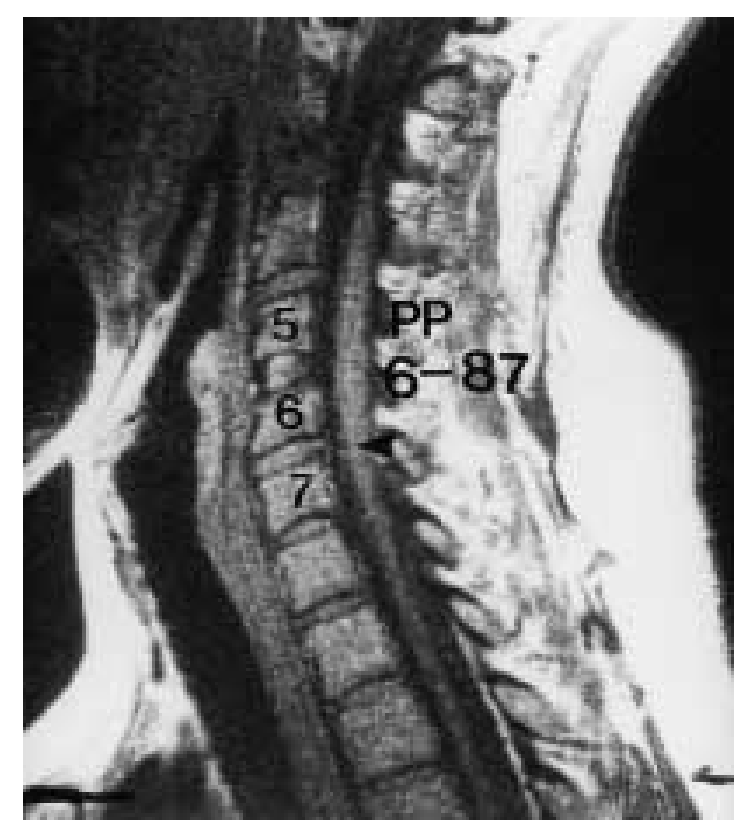

FIG. 8-C

$M$ agnetic resonance image made nine months postoperatively, showing new-onset disc herniation between the sixth and seventh cervical vertebrae (arrowhead); the herniation caused new-onset radiculopathy referable to the seventh cervical nerve root. 
older patients had advanced radiographic degenerative changes at an adjacent level at the time of the operation, and the symptomatic new disease developed within the first four years after the procedure ( $F i g s$. 6-A, 6-B, and 6-C).

In most of our patients, the gradual onset of radiographic degenerative changes at an adjacent level was followed by the development of new disease at that level as late as eighteen years after the operation (Figs. 7-A and 7-B). However, fourteen young patients (9 percent of all patients who were fifty years old or less) had early-onset adjacent-segment disease secondary to a new herniated nucleus pulposus at an adjacent level (Figs. 8-A , 8-B, and 8-C). These patients had few if any degenerative changes at the adjacent level before the new disc herniation developed.

On the basis of our findings in the current study, we recommend that degenerative changes at adjacent interspaces of the caudad part of the cervical spine be assessed carefully, especially in older patients. If the clinical findings suggest a relationship between the radiographic findings and the symptoms and if magnetic resonance imaging or myelography demonstrates neural element compression, these levels should be included in the decompression and arthrodesis. Patients who have clinical disease affecting multiple levels should not be managed with a single-level procedure. Patients should be informed that there is an approximately one in four chance of new disease developing at another level in the first ten years after an anterior cervical arthrodesis. We believe that this risk is related to the natural history of cervical spondylosis rather than to a failure of the operative technique and that it is probably unaffected by the operative management. Most of our patients in whom symptomatic adjacent-segment disease developed did not respond to nonoperative management, but the new symptoms usually resolved after anterior cervical decompression and arthrodesis.

\section{R eferences}

1. B aba, H .; Furusawa, N .; Imura, S.; K awahara, N.; T suchiya, H .; and Tomita, K.: L ate radiographic findings after anterior cervical fusion for spondylotic myeloradiculopathy. Spine, 18: 2167-2173, 1993.

2. B oden, S. D.; M cC owin, P. R .; D avis, D. O.; D ina, T. S.; M ark, A . S.; and Wiesel, S.: A bnormal magnetic-resonance scans of the cervical spine in asymptomatic subjects. A prospective investigation. J. B one and Joint Surg., 72-A : 1178-1184, Sept. 1990.

3. B ohlman, H. H.; E mery, S. E .; G oodfellow, D. B.; and Jones, P. K.: R obinson anterior cervical discectomy and arthrodesis for cervical radiculopathy. L ong-term follow-up of one hundred and twenty-two patients. J. B one and J oint Surg., 75-A : 1298-1307, Sept. 1993.

4. B rodke, D. S., and Z deblick, T. A .: M odified Smith-R obinson procedure for anterior cervical discectomy and fusion. Spine, 17 (Supplement 10): S427-S430, 1992.

5. B ull, J.; el G ammal, T.; and Popham, M.: A possible genetic factor in cervical spondylosis. B ritish J. Radiol., 42: 9-16, 1969.

6. Cherubino, P.; B enazzo, F.; B orromeo, U .; and Perle, S.: D egenerative arthritis of the adjacent spinal joint following anterior cervical spinal fusion: clinicoradiologic and statistical correlations. I talian J. O rthop. and Traumat., 16: 533-543, 1990.

7. Chow, D. H.; Luk, K. D.; Evans, J. H.; and Leong, J. C.: Effects of short anterior lumbar interbody fusion on the biomechanics of neighboring unfused segments. Spine, 21: 549-555, 1996.

8. Clements, D. H., and O' 'L eary, P. F.: A nterior cervical discectomy and fusion. Spine, 15: 1023-1025, 1990.

9. D ekutoski, M. B.; Schendel, M. J.; O gilvie, J. W.; O Isewski, J. M.; Wallace, L. J.; and Lewis, J. L.: Comparison of in vivo and in vitro adjacent segment motion after lumbar fusion. Spine, 19: 1745-1751, 1994.

10. D ohler, J. R .; Kahn, M. R.; and H ughes, S. P.: Instability of the cervical spine after anterior interbody fusion. A study on its incidence and clinical significance in 21 patients. A rch. O rthop. and Traumatic Surg., 104: 247-250, 1985.

11. G offin, J.; van Loon, J.; Van Calenbergh, F.; and Plets, C.: L ong-term results after anterior cervical fusion and osteosynthetic stabilization for fractures and/or dislocations of the cervical spine. J. Spinal D isord., 8: 500-508, 1995.

12. G ore, D. R ., and Sepic, S. B.: A nterior cervical fusion for degenerated or protruded discs. A review of one hundred fifty-six patients. Spine, 9: 667-671, 1984.

13. G uille, J. T.; M iller, A .; B owen, J. R .; Forlin, E .; and C aro, P. A .: The natural history of K lippel-Feil syndrome: clinical, roentgenographic, and magnetic resonance imaging findings at adulthood. J. Pediat. O rthop., 15: 617-626, 1995.

14. H enderson, C. M.; H ennessy, R . G.; Shuey, H . M., J r.; and Shackelford, E. G.: Posterior-lateral foraminotomy as an exclusive operative technique for cervical radiculopathy: a review of 846 consecutively operated cases. N eurosurgery, 13: 504-512, 1983.

15. Herkowitz, H. N.; Kurz, L. T.; and O verholt, D. P.: Surgical management of cervical soft disc herniation. A comparison between the anterior and posterior approach. Spine, 15: 1026-1030, 1990.

16. Hilibrand, A. S.; Yoo, J. U.; C arlson, G. D.; and Bohlman, H. H .: The success of anterior cervical arthrodesis adjacent to a previous fusion. Spine, 22: 1574-1579, 1997.

17. H unter, L. Y.; B raunstein, E. M .; and B ailey, R . W.: R adiographic changes following anterior cervical fusion. Spine, 5: 399-401, 1980.

18. Kaplan, E . L., and M eier, P.: N onparametric estimation from incomplete observations. J. A m. Statist. A ssn., 53: 457-481, 1958.

19. Kellgren, J. H ., and L awrence, J. S.: O steoarthrosis and disc degeneration in an urban population. A nn. R heumat. D is., 17: 388-397, 1958.

20. Lee, C. K., and Langrana, N. A .: L umbosacral spinal fusion. A biomechanical study. Spine, 9: 574-581, 1984.

21. L unsford, L. D.; B issonette, D. J.; Jannetta, P. J.; Sheptak, P. E .; and Z orub, D. S.: A nterior surgery for cervical disc disease. Part 1: Treatment of lateral cervical disc herniation in 253 cases. J. N eurosurg., 53: 1-11, 1980.

22. M cG rory, B. J., and Klassen, R. A .: A rthrodesis of the cervical spine for fractures and dislocations in children and adolescents. A long-term follow-up study. J. B one and J oint Surg., 76-A : 1606-1616, N ov. 1994.

23. Saal, J. S.; Saal, J. A .; and Y urth, E . F.: N onoperative management of herniated cervical intervertebral disc with radiculopathy. Spine, 21: 1877-1883, 1996.

24. White, A . A ., III, and Panjabi, M. M .: Clinical Biomechanics of the Spine. E d. 2, p. 98. Philadel phia, J. B. L ippincott, 1990.

25. Williams, J. L.; A llen, M. B., J r.; and H arkess, J. W.: L ate results of cervical discectomy and interbody fusion: some factors influencing the results. J. B one and Joint Surg., 50-A : 277-286, M arch 1968. 